\title{
Identifying patients at high risk for obstructive sleep apnoea syndrome in Nigeria: A multicentre observational study
}

\author{
Olufemi O. Desalu ${ }^{1}$, Cajetan C. Onyedum ${ }^{2}$, Adekunle O. Adeoti ${ }^{3}$, Joseph O. Fadare ${ }^{4}$, Emmanuel O. \\ Sanya ${ }^{5}$, Michael B. Fawale ${ }^{6}$, Hamzat A. Bello
}

1. Department of Medicine, University of Ilorin Teaching Hospital, Ilorin, Nigeria

2. Department of Medicine University of Nigeria Teaching Hospital, Enugu, Nigeria

3. Department of Pharmacology, Ekiti State University Teaching Hospital, Ado-Ekiti, Nigeria

4. Department of Medicine, Ekiti State University Teaching Hospital, Ado-Ekiti, Nigeria

5. Department of Medicine, Obafemi Awolowo University Teaching Hospital, Ile-Ife, Nigeria

Correspondence: Dr Olufemi O. Desalu (femuy1967@yahoo.co.uk)

\section{Background}

\section{Abstract}

Obstructive sleep apnoea is associated with significant health consequences. A significant proportion of hospitalized patients at risk for obstructive sleep apnoea were never identified and referred for polysomnography for diagnosis. The objective of this study was to determine the factors associated with high risk for obstructive sleep apnoea and use it to identify patients at risk for the condition in tertiary hospitals in Nigeria.

Methods

This was a multicentre observational study of adult patients hospitalized in three selected hospitals from 15th January to 17th March 2015. Berlin questionnaire and Epworth sleepiness scale were used to assess for obstructive sleep apnoea risk and excessive daytime sleepiness respectively. Additional questions on traditional risk factors for obstructive sleep apnoea were also obtained.

Results

Nine hundred and twenty-six patients were recruited into the study. Respondents' mean age was 44.3 years $\pm 15.2 y e a r s, 486$ $(52.5 \%)$ were females and $556(60.0 \%)$ had one or more medical co-morbidity and none of the patients had a previous diagnosis of obstructive sleep apnoea. Factors that were independently associated with high risk for obstructive sleep apnoea include systemic hypertension(aOR-10.33;95\%: CI 6.42-16.61), obesity(aOR-7.87;95\% CI: 4.33-14.29); excessive daytime sleepiness (aOR-3.77;95\% CI :2.28-6.22), tobacco smoking (aOR-2.99;95\% CI: 1.76-5.07), snoring in a first-degree relative (aOR-1.83;95\% CI: 1.19-2.81); and the use of sedative (aOR-1.82;95\% CI: 1.06-3.15).

Conclusions

This study shows that patients with systemic hypertension, obesity, excessive daytime sleepiness, history of smoking, snoring in a firstdegree relative and use of sedatives are at high risk of obstructive sleep apnoea. None of the patients at high risk had a previous diagnosis of sleep apnoea by a physician, highlighting the diagnostic challenges of this condition. The results of this study will assist health care professionals in early identification of individuals at risk of obstructive sleep apnoea and subsequent referral for a sleep study.

\section{Introduction}

Obstructive sleep apnoea (OSA) is the most common form of sleep-disordered breathing in adults and children and is associated with many other adverse health consequences, including an increased risk of death, ${ }^{1-2}$ significant socioeconomic burden and increased health care utilization. ${ }^{3-4}$ Well-documented predisposing factors for the condition include obesity, male gender, ethnicity and nasal obstruction; large tonsils (particularly in children). Other risk factors include an underactive thyroid gland; use of alcohol, tobacco, and sedatives and menopause in women. ${ }^{1-4}$ Screening questionnaires are used to identify subjects who are at high risk for OSA and diagnosis is made using an overnight polysomnography (PSG) in a sleep laboratory or at home by a portable diagnostic monitoring. ${ }^{5-6}$ The mainstay of management is CPAP in addition to behavioral therapy, physical or mechanical interventions 6. OSA affects $2-4 \%$ of the middle-aged male population and 2 percent of children ages 8 to 11 years in the USA. ${ }^{7-8}$ Although there is no national prevalence study of OSA in Nigeria, some hospital-based studies have demonstrated 17-40\% of adults are at high risk of OSA. ${ }^{9-13}$ The majority of the individuals with the condition under-report their symptoms and remain under diagnosed. ${ }^{8}$ This reason may be due to lack of awareness of sleep apnoea and diagnostic facilities in Nigeria, as there is only one sleep laboratory serving a population of 170 million and the cost is about 300-600 US dollars which cannot be afforded by most Nigerians. In the light of the above reasons, it is pertinent to identify factors associated with the risk of obstructive sleep apnoea to assist health care professionals in early identification of those at risk of obstructive sleep apnoea and subsequent referral for a sleep study. The objective of this study was to determine the factors associated with high risk for obstructive sleep apnoea and use it to identify patients at risk for the condition in tertiary hospitals in Nigeria.

\section{Methods}

\section{Study design}

This was a multicentre observational study involving adult patients admitted into the medical and surgical wards of selected Nigerian hospitals. The study was conducted over a period of two months from 15th January to 17th March 2015. 


\section{Study setting}

This study was conducted in Nigeria, a country located in West Africa and divided into 6 geopolitical zones. This survey setting was in three tertiary hospitals in three geopolitical zones of Nigeria and they were selected for reasons of easy coordination by the investigators. The hospitals were University of Nigeria Teaching Hospital, Enugu, Enugu State, University of Ilorin Teaching Hospital, Ilorin, Kwara State, and Ekiti State University, Ado-Ekiti, Ekiti State Nigeria.

\section{Sample size}

The minimum sample size was arrived at using the Cochran formula ${ }^{14}$ :

$\mathrm{N}=\mathrm{Z}^{2} \mathrm{pq} / \mathrm{d}^{2} \quad$ where,

$\mathrm{N}=$ sample size,

$\mathrm{Z}=$ standard normal deviation, usually set at 1.96 , which corresponds to the $95 \%$ confidence interval,

$\mathrm{p}=$ mean prevalence of adults at high risk of OSA in Nigeria $=25 \%,{ }^{,-13}$

$\mathrm{q}=(1-\mathrm{p})$, and

$\mathrm{d}=$ degree of accuracy desired, usually set at 0.05 .

The calculated minimum sample size was 288 . The estimated average patient turnover over a period of two months was less than 10,000. Cochran's correction formula was used to calculate the minimum sample size, as follows:

$\mathrm{N}=288 /(1+288 / 1280)=235$.

We anticipated a response rate of $90 \%$, design effect (DEFF) of 1.0 obtained by pretesting of the questionnaire, 3 age strata (18-44, 45-64, 65 years and above) and the final sample size was approximately 776. The design effect (DEFF) of 1.0 was used because age strata distribution across the centre does not significantly differ from each other despite the variation in the size of the centres. The minimum sample size was increased to 900 to increase the power of the study and be able to detect an odds ratio (OR) of at least 1.5. The estimated sample size was distributed proportionally based on the total number of bed and occupancy rate in the participating centres.

\section{Sampling method}

Systematic random sampling was adopted for the study. The hospital beds in the ward of participating hospital were given a specific number from 1 . Beds with even numbers were selected for the study to remove sampling bias. It is a strategy where every available subject that met the inclusion criteria had the probability of being selected until the survey period was over.

\section{Sample selection}

Sampling was undertaken by three trained resident doctors in internal medicine at each site during the study. Eligible patients were approached by the residents, who provided the subject information and consent form, and a verbal explanation of the study. The patients who gave their consent and met the inclusion criteria were recruited as study participants. The inclusion criteria were age 18 years and above, willingness to participate, admission into the medical or surgical wards, full consciousness and should not have mental impairment severe enough to impair simple conversation during the period of the study. Patients with language barriers to participation were also included whenever translation was available by an interpreter. Anonymity and confidentiality of the participants and their information were guaranteed by the investigators.

\section{Survey instrument}

A questionnaire was administered by trained residents in the department of internal medicine to obtain socio-demographic information, clinical information comorbidities, and risk factors for OSA. The patients who were unable to read English were helped with the questionnaire translated into the three major Nigerian languages. The translation and back translation was done at each hospital and piloted by the site coordinator and the resident administering the questionnaire to ensure that the semantic, idiomatic, conceptual, and crosscultural equivalence to the English version of the Berlin questionnaire and Epworth sleepiness scale. Fortunately, all the recruited subjects were able to speak and comprehend English or one of the three major languages. We also collected information from a person who shared the same bedroom and sleeps on the same bed with patients to substantiate the history of loud snoring and observed breathing cessation while sleeping. Anthropometric indices in the form of body weight $(\mathrm{kg})$ and height (centimeter) were measured and body mass index calculated and expressed in $\mathrm{kg} / \mathrm{m}^{2}$. Blood pressure was measured on two occasions, 5 minutes apart, sitting in a chair and hypertension was diagnosed with either a persistent blood pressure $\geq 140 / 90 \mathrm{mmHg}$ or the use of antihypertensive medications. ${ }^{15}$ Smoking was defined as ever smoking -smoked 100 cigarette stick in a lifetime (currently or formerly). Regular alcohol use was defined as taking an alcoholic beverage at least once every 7 days 12 .

\section{Risk of OSA}

The risk of OSA and excessive daytime sleepiness were established by a validated Berlin questionnaire 6 and Epworth sleepiness scale respectively 16 . In scoring the questions: any answer is scored as a positive or negative response. Based on the scoring they were sub-classified into three scoring categories: predetermination of a high risk and low risk of OSA using the Berlin Questionnaire was determined on the basis of the responses in 3 symptom categories. In category 1 , high risk was defined as persistent symptoms ( $>3$ to 4 times/week) for $\geq 2$ questions about snoring. In category 2 , high risk was defined as persistent ( $>3$ to 4 times/week) daytime tiredness or fatigue. In category 3 , high risk was defined as a history of high blood pressure or a body mass index $>30 \mathrm{~kg} / \mathrm{m}^{2}$. To be considered at high risk of OSA, a patient had to qualify for $\geq 2$ symptom categories. Those who denied having persistent symptoms or who qualified for only one symptom category were placed in the lower risk group. Epworth Scoring Scale (ESS) ranges from 0 to 24 and scores $>10$ are considered associated with excessive daytime sleepiness while 1-6 is "good" and 7-10 "okay". Where possible, the interviewer notified the participants about their risk of OSA and excessive daytime sleepiness and the need for further evaluation.

\section{Data analysis}

The data obtained were analyzed using SPSS statistical software version 21 (SPSS Inc., Chicago, IL, USA). Univariate analyses were used to examine the general characteristics of the patients. The odds ratios for factors associated with high risk for OSA were calculated using univariate logistic regression analysis. Variables with $\mathrm{P}<0.10$ were included in the multivariate model. A P value of $<0.05$ was considered statistically significant. 
Table 1: Characteristics of study patients

\begin{tabular}{|c|c|}
\hline Characteristics & Mean \pm SD or $n(\%)$ \\
\hline Mean age in years & $44.3 \pm 15.2$ \\
\hline \multicolumn{2}{|l|}{ Age range } \\
\hline $18-44$ & $486(52.5)$ \\
\hline $45-64$ & $330(35.6)$ \\
\hline $65+$ & $110(11.9)$ \\
\hline Mean body mass index $\left(\mathrm{kg} / \mathrm{m}^{2}\right)$ & $24.3 \pm 4.6$ \\
\hline Epworth Sleepiness Scale rating & $6.9 \pm 3.9$ \\
\hline \multicolumn{2}{|l|}{ Sex } \\
\hline Male & $440(47.5)$ \\
\hline Female & $486(52.5)$ \\
\hline $\begin{array}{l}\text { Presence of chronic medical } \\
\text { condition }\end{array}$ & $556(60.0)$ \\
\hline Hypertension & $326(35.3)$ \\
\hline Type 2 diabetes mellitus & $100(10.8)$ \\
\hline Obesity & $104(11.2)$ \\
\hline Peptic ulcer & $112(12.1)$ \\
\hline Asthma & $52(5.6)$ \\
\hline Insomnia & $54(5.8)$ \\
\hline Stroke & $28(3.0)$ \\
\hline Heart failure & $38(4.1)$ \\
\hline COPD & $32(3.5)$ \\
\hline Rhinitis & $18(1.7)$ \\
\hline Others & $128(13.8)$ \\
\hline Previous OSA diagnosis & 0 \\
\hline Use of sedatives & $110(11.9)$ \\
\hline Tobacco smoking & $132(14.2)$ \\
\hline Alcohol consumption & $262(28.3)$ \\
\hline $\begin{array}{l}\text { First-degree relative with } \\
\text { snoring or excessive sleepiness }\end{array}$ & $396(42.8)$ \\
\hline
\end{tabular}

$\mathrm{SD}=$ standard deviation; $\mathrm{COPD}=$ chronic obstructive pulmonary disease; OSA = obstructive sleep apnoea

\section{Ethical approval}

The study was approved by the ethics and research committees of the three study institutions.

\section{Results}

\section{Characteristics of the study participants}

A total of 1000 patients admitted to the medical and surgical wards of the selected hospitals were informed about the study; only 926 met the inclusion criteria and were enrolled in the study with a completion rate of $92.6 \%$. The mean age of the enrolled patients was 44.3 years with a standard deviation of 15.2 years. Four hundred and eighty-six (52.5\%) were female and $556(60.0 \%)$ had one or more medical morbidity with $326(35.2 \%)$ having hypertension which was the commonest medical morbidity (Table 1).

\section{High risk for OSA}

One hundred and forty-two patients (15. 4\%) had excessive daytime sleepiness (EDS) i.e. An Epworth Sleepiness Scale score of >10 and $180(19.4 \%)$ had a Berlin Questionnaire score indicative of high risk for OSA. None of the patients with EDS or high risk for OSA had a previous diagnosis of obstructive sleep apnoea by a doctor.The frequency of high risk for OSA was $27.0 \%$ in UNTH in South East, $18.3 \%$ in UITH in North Central and $14.6 \%$ in EKSUTH in the South West Nigeria. There was a significant difference in the prevalence of high risk for OSA among these hospitals ( $p$ value of 0.003 ). The risk of OSA and excessive daytime sleepiness, respectively, were also higher among the male participants compared with the female (Table 2).

\section{Factors associated with high risk for OSA}

To determine the factors associated with high risk for OSA, a multivariate logistic regression analysis was performed for the traditional risk factors for OSA. Systemic hypertension had an odd ratio (OR) of 10.33(95\% CI 6.42-16.61). Obesity (OR- 7.87; 95\% CI: 4.33-14.29), excessive daytime sleepiness (OR-3.77; 95\% CI: 2.28-6.22), tobacco smoking (OR-2.99; $95 \% \mathrm{CI}: 1.76-5.07)$, snoring in first-degree relative (OR1.83; 95\% CI: 1.19-2.81), and the use of sedative (OR-1.82; 95\% CI: 1.06-3.15) (Table 3). Male gender and the use of alcohol were associated with high risk of sleep apnoea on univariate analysis, but they were not statistically significant after multivariate analysis.

\section{Discussion}

The main findings of this study showed that the factors independently associated with high risk for OSA were systemic hypertension, obesity, tobacco smoking, snoring in the first-degree relative, in addition to the use of sedative and excessive daytime sleepiness.

In this study, high risk for OSA using Berlin questionnaire was $19 \%$, and this is comparable with the other studies in the adult population of Nigeria. ${ }^{9-13}$ We also found that systemic hypertension independently predicted high OSA risk and that hypertensive patients had tenfold increase in the odds of high risk for sleep apnoea compared with nonhypertensive. This is similar to the finding of Ozdemir L, et al. in Turkey who found a ninefold increase. ${ }^{17}$ Other studies in Nigeria and elsewhere have also found a strong association between sleep apnoea and hypertension ${ }^{9-12,18,19}$ and resistant hypertension. ${ }^{20}$ The existence of an association does not, however, necessarily imply causality. The seeming association between high OSA risk and hypertension in this study may actually be due to colinearity and not a true association because the history of hypertension is one of the items in the Berlin Questionnaire. This, however, does not remove the fact that hypertension is strongly associated with OSA itself. ${ }^{9-12,18-20}$ The most recent Joint National Committee on the Detection and Management of Hypertension recognized OSA as an identifiable cause of hypertension because of the compelling evidence. ${ }^{15}$ Obstructive sleep apnoea syndrome has been associated with a higher than normal cardiovascular problems as a result of nocturnal "non-dipping of blood pressure in normotensive and hypertensive individuals. ${ }^{20-21}$

This study revealed that obese patients were eight times more likely to develop a high risk for obstructive sleep apnoea when compared with non-obese patients. The Wisconsin Sleep Cohort study reported that a standard deviation difference in body mass index (BMI) was associated with a fourfold increase in OSA prevalence. ${ }^{22}$ Our result is also in tandem with other studies across the globe., ${ }^{9,10,20,22-25}$ Obesity 
Table 2: Risk of obstructive sleep apnoea and excessive daytime sleepiness (EDS) according to sex

\begin{tabular}{lccc}
\hline Risk for sleep apnoea \& EDS & Male $(\mathbf{n}=\mathbf{4 4 0})$ & Female $(\mathbf{n}=\mathbf{4 8 6})$ & All subjects $(\mathbf{N}=926)$ \\
\hline Risk for sleep apnoea* & & & \\
$\quad$ Low risk & $342(77.7)$ & $404(83.1)$ & $746(80.6)$ \\
$\quad$ High risk & $96(22.3)$ & $82(16.9)$ & $180(19.4)$ \\
Excessive daytime sleepiness $(\mathrm{ESS}>10)^{*}$ & $70(15.9)$ & $72(14.8)$ & $142(15.4)$ \\
\hline
\end{tabular}

Data are presented as N (\%); ESS = Epworth Sleepiness Scale rating;

*difference between males and females was not significant $(\mathrm{P}>0.05)$

Table 3: Factors associated with a high risk of obstructive sleep apnoea

\begin{tabular}{lccc}
\hline Variable & $\begin{array}{c}\text { Unadjusted } \\
\text { OR }(\mathbf{9 5 \%} \mathbf{C I})\end{array}$ & $\begin{array}{c}\text { Adjusted } \\
\text { OR }(\mathbf{9 5 \%} \mathbf{C I})\end{array}$ & P-value \\
\hline Age & $1.00(1.04$ to 1.04$)$ & $0.99(0.98$ to 1.01$)$ & 0.44 \\
Male gender & $1.41(1.02$ to 1.96$)$ & $1.52(0.93$ to 2.46$)$ & 0.093 \\
Tobacco smoking & $2.39(1.59$ to 3.59$)$ & $2.99(1.76$ to 5.07$)$ & $<0.001$ \\
Alcohol consumption & $1.72(1.22$ to 2.43$)$ & $1.45(0.85$ to 2.49$)$ & 0.17 \\
Snoring in first-degree relative & $2.99(2.11$ to 4.21$)$ & $1.83(1.19$ to 2.81$)$ & 0.006 \\
Hypertension & $17.85(11.52$ to 27.64$)$ & $10.33(6.42$ to 16.61$)$ & $<0.001$ \\
Obesity & $6.83(4.43$ to 10.55$)$ & $7.87(4.33$ to 14.29$)$ & $<0.001$ \\
Type 2 diabetes mellitus & $1.54(0.70$ to 3.89$)$ & $1.59(0.75$ to 3.34$)$ & 0.23 \\
Use of sedatives & $3.66(2.40$ to 5.58$)$ & $1.82(1.06$ to 3.15$)$ & 0.030 \\
Excessive daytime sleepiness $(\mathrm{ESS}>10)$ & $4.71(3.21$ to 6.92$)$ & $3.77(2.28$ to 6.22$)$ & $<0.001$ \\
\hline
\end{tabular}

$\mathrm{OR}=$ odds ratio; ESS $=$ Epworth Sleepiness Scale rating

can cause airway narrowing as a result of an excess of fat tissue around the neck.

The result of this study also revealed that respondents who have EDS were four times more likely to be at risk of OSA and this observation is similar to findings by Ozoh et al. in Lagos, Nigeria. ${ }^{12}$ Excessive daytime sleepiness occurs in OSA due to sleep fragmentation from hypoxemia induced by upper airway obstruct. Excessive daytime sleepiness is of major public health concern as it increases the risk of road traffic accidents and other occupational injuries

We also found that patients who smoked tobacco were three times likely to be at high risk of sleep apnoea. Several other studies have documented a strong association between sleep apnoea and smoking. ${ }^{10,22,24,26}$ Smoking is one of the strongest risk factors for cardiovascular disease and may add to the cardiovascular risk associated with OSA.

The patients that reported the use of sedatives were two times more likely to be at risk of OSA when compared with those that never used such medication in this study. The increased rate of sedative use found among patients with sleep apnoea may be due to the presence of underlying obesity, which is a major risk factor for obstructive sleep apnoea among men and the high prevalence of obesity among sleep apnoea patients. 9,10,20,22-25 Morbidly obese patients used a lot of sedatives because they experienced a high level of insomnia due to nocturnal or muscular pains, which are complicated in obese individuals. ${ }^{27-28}$ Nocturnal sleep fragmentations may also be an incentive for use of hypnotics. ${ }^{27}$

This study also revealed a strong association between history of snoring in the first degree relatives and high risk for OSA. Other studies have reported a similar association in their findings. ${ }^{29-30}$ The role of familial inheritance is attributable to craniofacial or cephalometric anomalies which include narrower upper airways with retroposed maxillae and mandibles and long soft palates with wider uvula found in relatives. $^{30}$

The odd of high OSA risk was higher with the male gender compared with the female gender on univariate analysis, but this gender difference disappeared on multivariate analysis. The increased odd of high OSA risk with the male gender is in agreement with the results of other studies. ${ }^{1,10}$ This male predominance can be due to gender differences in the tobacco smoking, alcohol use, adipose tissue distribution, upper airway anatomy and muscle function, control of ventilation, and the effects of sex hormones and leptin.

One of the most striking findings of this study is that none of 926 patients had a previous diagnosis of obstructive sleep apnoea by a doctor. Similar observation was noted in previous studies in the country about the challenges encountered in the diagnosis of this condition. ${ }^{12,31}$ The under diagnosis of OSA may be due to under reporting of symptoms by the patients, because most patients are not aware that it is a manifestation of a medical problem. ${ }^{31}$ Furthermore, it may be due to poor awareness and knowledge regarding obstructive sleep apnoea among the physicians and those in medical training. ${ }^{32-33}$ The implication of this finding is that there is a need to improve training on sleep disorders in Nigeria both at the medical school, continuing medical education programs and during residency training.

Finally, we also found a higher prevalence of high risk for sleep apnoea in the participating hospital in the south east compared to the hospitals in the south west and the north 
central part of the country. This variation can be explained from high prevalence of systemic hypertension and obesity in the south east and also on the level of urbanization. ${ }^{31,34,35}$ However, this discovery may require further exploration in a multiregional community based study.

\section{Strengths and limitations}

The strength of our study is based on the large sample size of the respondents. Despite the aforementioned strength, the present study has some potential limitations which include the possible recall bias on the part of the patient and their relatives which affect their level of reporting of symptoms and actual prevalence. This problem was minimized with an additional collection of information from a person who shared the same bedroom and sleeps on the same bed. Another potential limitation is the high level of comorbidities that could potentially overestimate the burden of OSA in this population. Thus a future population-based epidemiologic study of sleep apnoea confirmed by sleep study in all geopolitical zones is recommended to provide a better understanding of the condition. We are of the opinion that these limitations may not have sufficiently impacted negatively on the main results of this study.

\section{Conclusions}

This study shows that patients with systemic hypertension, obesity, excessive daytime sleepiness, history of smoking, snoring in a first-degree relative and use of sedatives are at higher risk of obstructive sleep apnoea. None of the patients at high risk had a previous diagnosis of sleep apnoea by a physician, highlighting diagnostic challenges of this condition. The results of this study will assist health care professionals in early identification of individuals at risk of obstructive sleep apnoea and subsequent referral for a sleep study.

\section{Acknowledgements}

We want to recognize the efforts of our colleagues, internal medicine residents and matrons in charge of the wards in all the selected hospitals for their assistance during the process of data collection and thank all the patients that participated in the study.

\section{Competing interests}

All authors declare that they have no competing interests related to this work. This study was carried out without any funding support. This study was funded through contributions from all coinvestigators.

\section{References}

1. Al Lawati NM, Patel SR, Ayas NT. Epidemiology, risk factors, and consequences of obstructive sleep apnea and short sleep duration. Prog Cardiovasc Dis 2009; 51:285-293.

2. Young T, Finn L, Peppard PE, et al. Sleep-disordered breathing and mortality: eighteen-year follow-up of the Wisconsin sleep cohort. Sleep 2008; 31:1071-1078.

3. AlGhanim N, Comondore VR, Fleetham J, Marra CA, Ayas NT. The economic impact of obstructive sleep apnea. Lung 2008; 186:7-12.

4. Albarrak M, Banno K, Sabbagh AA, et al. Utilization of health care resources in obstructive sleep apnea syndrome: a 5-year follow-up study in men using CPAP. Sleep 2005; 28: 1306-1311.

5. Collop NA, Anderson WM, Boehlecke B, et al.Clinical Guidelines for the Use of Unattended Portable Monitors in the Diagnosis of Obstructive Sleep Apnea in Adult Patients. J Clin Sleep Med 2007; 3: 737-747.
6. Netzer NC, Stoohs RA, Netzer CM, Clark K, Strohl KP. Using the Berlin Questionnaire to identify patients at risk for the sleep apnea syndrome. Ann Intern Med. 1999; 131:485-491.

7. Rosen CL, Larkin EK, Kirchner HL, et al. Prevalence and risk factors for sleep-disordered breathing in 8- to 11-year-old children: association with race and prematurity. J Pediatr 2003; 142:383-389.

8. Young T, Peppard PE, Gottlieb DJ. Epidemiology of obstructive sleep apnea: a population health perspective. Am J Respir Crit Care Med 2002; 165:1217-1239.

9. Adewole OO, Hakeem A, Erhabor G, Fola A, Ajonwon Z. Obstructive sleep apnoea among adults in Nigeria. J Niger Med Assoc. 2009; 101:720-725.

10. Sogebi OA, Ogunwale. Risk factors of obstructive sleep apnea among Nigerian outpatients.Braz J Otorhinolaryngol. 2012; 78:27-33.

11. Akintunde AA, Okunola OO, Oluyombo R, Oladosu YO, Opadijo OG. Snoring and risk for obstructive sleep apnea among Nigerians with hypertensive: Prevalence and clinical correlates. Pan Afr Med J. 2012; $11: 75$.

12. Ozoh OB, Okubadejo NU, Akinkugbe AO, et al. Prospective assessment of the risk of obstructive sleep apnea in patients attending a tertiary health facility in Sub-Saharan Africa. Pan Afr Med J 2014;17:302.

13. Obaseki DO, Kolawole BA, Gomerep SS, et al. Prevalence and predictors of obstructive sleep apnea syndrome in a sample of patients with type 2 Diabetes Mellitus in Nigeria. Niger Med J. 2014;55(1):248 .

14. Bartlett JE, Kotrlik JW, Higgins C. Organizational research: Determining appropriate sample size for survey research. Inf Technol Learn Perform J. 2001; 19:43-50.

15. Chobanian AV, Bakris GL, Black HR, et al.; National Heart, Lung, and Blood Institute Joint National Committee on Prevention, Detection, Evaluation, and Treatment of High Blood Pressure. NationalHigh Blood Pressure Education Program Coordinating Committee.The Seventh Report of the Joint National Committee on Prevention, Detection, Evaluation, and Treatment of High Blood Pressure: the JNC 7 report. JAMA 2003; 289:2560-2572.

16. Johns MW. A new method for measuring daytime sleepiness: the Epworth sleepiness scale. Sleep 1991; 14:540-545.

17. Ozdemir L, Akkurt I, Sümer H, et al.The prevalence of sleep related disorders in Sivas, Turkey. Tuberk Toraks. 2005; 53:20-27.

18. Taj F, Aly Z, Arif O, Khealani B, Ahmed M: Risk for sleep apnea syndrome in Pakistan: a cross-sectional survey utilizing the Berlin questionnaire. Sleep Breath 2009, 13:103-106

19. Mirrakhimov AE, Sooronbaev T, Mirrakhimov EM. Prevalence of obstructive sleep apnea in Asian adults: a systematic review of the literature. BMC Pulm Med. 2013. 23; 13:10.

20. Dede M, Pandey A, Zizi F, et al. Resistant hypertension and obstructive sleep apnea in the primary-care setting. Int J Hypertens. 2011; 2011:340929. doi: 10.4061/2011/340929.

21. Parati G, Lombardi C, Hedner J, Bonsignore MR, Grote L, Tkacova R, et al. ERS/ESH task force report recommendations for the management of patients with obstructive sleep apnoea and hypertension. Eur Respir J 2013; 41: 523-538

22. Young T, Palta M, Dempsey J, Skatrud J, Weber S, Badr S. The occurrence of sleep disordered breathing among middle-aged adults. N Engl J Med 1993; 328:1230-1235.

23. Noal RB, Menezes AM, Canani SF, Siqueira FV. Habitual snoring and obstructive sleep apnea in adults: population-based study in Southern Brazil. Rev Saude Publica. 2008; 42:224-233.

24. Young T, Skatrud J, Peppard PE. Risk factors for obstructive sleep apnea in adults. JAMA 2004; 291:2013-2016. 
25. Hiestand DM, Britz P, Goldman M, Phillips B. Prevalence of symptoms and risk of sleep apnea in the US population: Results from the national sleep foundation sleep in America 2005 poll. Chest. 2006; 130:780-786.

26. Kashyap R1, Hock LM, Bowman TJ. Higher prevalence of smoking in patients diagnosed as having obstructive sleep apnea. Sleep Breath. 2001;5(4):167-72

27. Tikkinen KA, Auvinen A, Johnson TM 2nd, Weiss JP, Keränen T, Tiitinen A, et al. A systematic evaluation of factors associated with nocturia - the population-based FINNO study. Am J Epidemiol 2009; 170:361-368?

28. Holliday KL, McWilliams DF, Maciewicz RA, Muir KR, Zhang W, Doherty M. Lifetime body mass index, other anthropometric measures of obesity and risk of knee or hip osteoarthritis in the GOAL casecontrol study. Osteoarthritis Cartilage 2011; 19:37-

29. Amra B, Bahaee FS, Amini M, Golshan M, Fietze I, Penzel T. Sleep Apnea Symptoms in Diabetics and their First Degree Relatives. Int J Prev Med. 2012; 3:95-101.

30. Mathur R, Douglas NJ. Family studies in patients with the sleep apnea-hypopnea syndrome. Ann Intern Med. 1995;122:174-178

31. Desalu OO, Onyedum CC, Sanya EO, Fadare JO, AdeotiAO, Salawu FK, et al Prevalence, Awareness and Reporting of Symptoms of Obstructive Sleep Apnoea among Hospitalized Adult Patients in Nigeria: A Multicenter Study. Ethiopian Journal of Health Sciences 2016; 26:321-330 47 .
32. Ozoh OB, Iwuala SO, Desalu OO, Ojo OO, Okubadejo NU. An Assessment of the Knowledge and Attitude of Graduating Medical Students in Lagos, Nigeria, Regarding Obstructive Sleep Apnea. Annals of American Thoracic Society.2015; 12 (9): 1358-1369

33. Ozoh OB, Ojo OO, Iwuala SO, Akinkugbe AO, Desalu OO, Okubadejo NU. Is the knowledge and attitude of physicians in Nigeria adequate for the diagnosis and management of obstructive sleep apnea? Sleep Breath. 2016; 12:1-7

34. Murthy GV, Fox S, Sivasubramaniam S, Gilbert CE, Mahdi AM, Imam AU et al Nigeria National Blindness and Visual Impairment study group. Prevalence and risk factors for hypertension and association with ethnicity in Nigeria: results from a national survey.Cardiovasc $\mathrm{J}$ Afr. 2013;24(9-10):344-50

35. National Population Commission (NPC) [Nigeria] and ICF International. 2014. Nigeria Demographic and Health Survey 2013. Abuja, Nigeria, and Rockville, Maryland, USA: NPC and ICF International. 